\title{
ESTRATÉgIAS PEDAGÓgICAS FUNDAMENTADAS NA PESQUISA-AÇÃO PARTICIPATIVA PARA A SENSIBILIZAÇÃO DE EDUCANDOS DE ESCOLAS DO CAMPO DE UBERLÂNDIA (MG) SOBRE O TEMA “ÁGUA”
}

\author{
Maraína Souza Medeiros ${ }^{1}$ \\ Ingrid da Silva Pacheco ${ }^{2}$ \\ Edyane Tássia Padilha ${ }^{3}$ \\ Layla Giovanna Girotto ${ }^{4}$ \\ Andressa Costa e Silva Cabral ${ }^{5}$ \\ Fábio Augusto do Amaral ${ }^{6}$ \\ Helder Eterno da Silveira ${ }^{7}$ \\ Sheila Cristina Canobre ${ }^{8}$
}

\begin{abstract}
Resumo
Este estudo teve como objetivo elaborar e executar estratégias pedagógicas como prática da Educação Ambiental para orientar e sensibilizar os educandos de três escolas do campo de Uberlândia-MG a partir do tema água. No diagnóstico prévio das demandas das escolas do campo investigadas, estratégias pedagógicas foram adotadas, fundamentadas na pesquisa-ação participativa e na abordagem educativa conteudista-racionalista. As estratégias pedagógicas desenvolvidas foram: colagem e pintura; montagem de murais; jogo de perguntas e respostas; cartilha; e vídeos educativos. As propostas aplicadas pelos autores (educadores ambientais) nas três escolas do campo, até então atendidas, exploraram a conscientização dos alunos em relação à poluição, à contaminação, à importância, a doenças e ao desperdício de água com enfoque no uso desta em atividades cotidianas. A análise dos resultados revelou que estratégias pedagógicas motivadoras são necessárias para a conscientização de educandos, mas que devem ser contínuas para reforçar a problemática ambiental da crise hídrica que assola o mundo.
\end{abstract}

Palavras-chave: Água. Educação ambiental. Estratégias pedagógicas. Escola do campo.

\section{PEDAGOGICAL STRATEGIES BASED ON RESEARCH- PARTICIPATORY ACTION, FOR AWARENESS OF STUDENTS FROM UBERLÂNDIA (MG, BRAZIL) FIELD SCHOOLS ABOUT WATER ISSUES}

\footnotetext{
Abstract

The present study aims to elaborate and implement pedagogical strategies, such as environmental education pratice, to orient and sensitize students from three field schools of Uberlândia (MG, Brazil) to the "water" theme. In previous diagnosis about the demands of field schools, pedagogical strategies were adopted based on research-participatory action and on the educational content-rationalist approach. The pedagogical strategies developed were: collage and painting; bulletin board decoration; quiz; textbook; and educational videos. The authors' proposal (who were environmental educators) in the available field schools, was to

${ }^{1}$ Mestre em Meio Ambiente e Qualidade Ambiental, Universidade Federal de Uberlândia (UFU)

${ }^{2}$ Discente em Engenharia Ambiental, Universidade Federal de Uberlândia (UFU)

${ }^{3}$ Discente em Engenharia Ambiental, Universidade Federal de Uberlândia (UFU)

${ }^{4}$ Discente em Engenharia Ambiental, Universidade Federal de Uberlândia (UFU)

${ }^{5}$ Engenheira Ambiental, Universidade Federal de Uberlândia (UFU)

${ }^{6}$ Prof Dr Instituto de Química, Universidade Federal de Uberlândia (UFU)

${ }^{7}$ Prof. Dr. Instituto de Química, Universidade Federal de Uberlândia (UFU)

${ }^{8}$ Prof $^{\mathrm{a}}$. Dra . Instituto de Química, Universidade Federal de Uberlândia (UFU)
} 
explore students' awareness regarding pollution, contamination, diseases, water waste and this liquid's importance, focusing on everyday activities and use. The analysis of the results showed that motivating pedagogical strategies is necessary for students' awareness, but they should become continuous to enhance consciousness about environmental problems and the hydric crises that affects the world.

Keywords: Water. Environmental education. Pedagogical strategies. Field school.

\section{ESTRATEGIAS PEDAGÓGICAS BASADAS EN LA INVESTIGACIÓN-ACCIÓN- PARTICIPANTE PARA LA SENSIBILIZACIÓN DE ALUMNOS DE ESCUELAS DEL CAMPO DE UBERLANDIA-MG SOBRE EL TEMA DEL AGUA}

\section{Resumen}

El presente estudio tuvo como objetivo elaborar y ejecutar estrategias pedagógicas, como práctica de la Educación Ambiental, para orientar y sensibilizar los estudiantes de tres escuelas del campo de Uberlândia-MG, a partir de la temática agua. En el diagnóstico previo de las demandas de las escuelas de campo investigadas, estrategias pedagógicas fueron adoptadas, basadas en la investigación-acción-participante y abordaje educativo contenidoracionalista. Las estrategias pedagógicas desarrolladas fueron: Pegado y pintura; Montaje en murales; Juguete de preguntas y respuestas; Cartilla y; Videos educativos. Las propuestas aplicadas por los autores (educadores ambientales) en las tres escuelas en el campo, atendidas hasta el momento, exploraron la concienciación de los alumnos relativa a la polución, contaminación, importancia, enfermedades y el desperdicio de agua con enfoque sobre el uso de esta en actividades cotidianas. El análisis de los resultados ha revelado que estrategias pedagógicas motivadoras son potenciales para la concienciación de estudiantes, pero que deben de hacerse continuas para reforzar la problemática ambiental de la crisis hídrica que asola el mundo.

Palabras-clave: Agua. Educación Ambiental. Estrategias pedagógicas. Escuela del Campo.

\section{Introdução}

A qualidade da água vem sendo ao longo dos anos perturbada por diversas ações antropogênicas. Os primeiros problemas relacionados aos recursos hídricos foram doenças provocadas pela ingestão e/ou contato com água não tratada (ausência de saneamento básico, que ocorre principalmente em regiões tropicais), com organismos patogênicos, o que gera uma reação em cadeia de causa e efeito de difícil solução. Ademais, a rápida urbanização contribuiu para gerar poluição concentrada, preocupantes problemas de drenagem em função da inadequada deposição do lixo (resíduos sólidos urbanos), assoreamento de corpos d'água e consequente redução da capacidade de escoamento das águas (MORAES; JORDÃO, 2002). Para mitigar tais problemas ambientais que acometem água, solo, atmosfera e biota, vários debates sobre educação ambiental (EA) surgiram ao longo das últimas décadas, tanto no contexto mundial quanto no contexto nacional, como resultado das preocupações de vários setores da sociedade sobre as questões ambientais (BEZERRA, 2007). Nesse sentido, é preciso mencionar alguns eventos que trilharam o surgimento da EA no mundo e no Brasil e suas principais contribuições no contexto das questões ambientais.

A primeira utilização do termo "educação ambiental" ocorreu em um evento de educação promovido pela Universidade de Keele, no Reino Unido, em 1965. Alguns anos depois, em 1972, na cidade de Estocolmo, ocorreu a Conferência das Nações Unidas sobre o Ambiente Humano, que ressaltava a importância de se trabalhar ambiente e educação de 
forma vinculada. Após esse evento, a Organização para a Educação, Ciência e Cultura (Unesco) e Programa das Nações Unidas para o Meio Ambiente (PNUMA) elaboraram o Programa Internacional de educação ambiental (Piea), responsável por promover encontros regionais e nacionais sobre o tema. Então, em 1975, ocorreu o I Seminário Internacional de educação ambiental, em Belgrado. O principal propósito desse evento era discutir a EA como processo educativo amplo capaz de modificar as atitudes humanas em prol de uma vida sustentável no planeta. Desde então, vários outros eventos ocorreram para discutir educação ambiental. No Brasil, em especial, o debate sobre a EA se iniciou tardiamente quando comparado a outros países, sendo em meados da década de 1980 que ganhou dimensão relevante no país, principalmente com sua inclusão na Constituição Federal de 1988 (LOUREIRO, 2009).

Neste cenário, a educação ambiental foi ganhando importância no âmbito escolar. Por definição, a EA deve originar-se da educação e, quando constatada, refere-se a um projeto que abranja toda a escola, a comunidade e os movimentos populares, em prol da preservação da vida, solucionando problemas socioambientais e criando condições mais sustentáveis de vida no planeta (SANTANA; FREITAS, 2012). Para Siddiqui e Khan (2015), a EA oferece aos alunos habilidades, experiências e conhecimentos quanto à realidade, tornando-os conscientes de suas ações e capazes de gerir recursos naturais.

Com relação à temática ambiental água, assunto constante no cotidiano dos cidadãos, sendo abordado em diversas mídias e segmentos sociais, além de estar presente em documentos oficiais, tais como currículos escolares, legislações, livros didáticos e objeto de pesquisa para projetos pedagógicos. Existem sim projetos especiais em educação ambiental, mas não especificamente sobre o tema água. Em contrapartida, educadores ambientais têm mencionado a crescente degradação dos corpos d'água em função de ações antrópicas, o que revela a necessidade de ações emergentes para fins de recuperação, conservação e preservação dos recursos hídricos existentes (FREITAS; MARIN, 2015). Sobre pesquisas em educação ambiental, estas são fortemente observadas em produções acadêmicas em todo território brasileiro, com várias temáticas abordadas nos mais diversos ambientes educativos e envolvendo grupos sociais distintos (SOUZA; SALVI, 2012). Com base nessa realidade, são apresentadas e discutidas a seguir as principais produções acadêmicas no Brasil e no estado de Minas Gerais sobre EA.

\subsection{Estudos sobre educação ambiental em Minas Gerais, Brasil}

A educação ambiental é imprescindível, seja na zonal rural ou na cidade, pois impulsiona o desenvolvimento de uma nova consciência no homem e na mulher das relações com seu meio ambiente, e também produz novas condutas que levam as pessoas a se preocuparem com questões ambientais. Mesmo sendo escassos os problemas ambientais no meio rural, é necessário trabalhar atividades voltadas para a EA, principalmente em escolas, como forma de garantir a sensibilização do indivíduo para que viva em equilíbrio com o meio em que habita (SANTOS et al., 2010).

Sobre a prática da EA no meio rural, o projeto de EA nas escolas das populações ribeirinhas do Alto Rio Doce na Zona da Mata de Minas Gerais, iniciado em abril de 2004, é desenvolvido na Escola Rural Antônio Cassimiro da Silva, na comunidade Casa Nova, município de Guaraciaba (MG), e na Escola Municipal Doutor Raimundo Campos Viana Filho, no município de Pedra da Anta (MG). Em ambas há alunos oriundos de áreas que seriam atingidas pela construção de uma usina hidrelétrica. Para realização de um diagnóstico socioambiental, foi desenvolvido um concurso de desenhos com os alunos, em que se pôde perceber que o rio é essencial para a sobrevivência deles, já que foi o elemento mais desenhado. Diante destes resultados, o grupo de pesquisadores participantes do projeto 
sugeriu uma discussão sobre a importância econômica e biodiversidade do corpo hídrico, e como cuidar dele, obtendo respostas que mostram que as crianças se preocupam com a preservação do meio ambiente como fonte da vida e meio de subsistência. Dessa maneira, os autores contribuíram para aumento significativo da conscientização ambiental e da autoestima desses estudantes (ROTHMAN et al., 2004).

Em contrapartida, o projeto conduzido por Miranda et al. (2009) desenvolveu suas atividades em escolas urbanas e do campo do município de São Roque de Minas (MG), a fim de trabalhar a proteção ambiental de uma espécie aquática ameaçada de extinção (patomergulhão). O Programa Pato-mergulhão, para a prática da educação ambiental, foi criado em 2011 para proteger a espécie Mergus octosetaceus cuja principal população habita a região da Serra da Canastra e está severamente ameaçada de extinção. No projeto, foram realizados cinco ciclos de oficinas, nos quais houve grande interesse dos alunos nas atividades e nos debates propostos sobre os temas tratados. As ações desenvolvidas foram voltadas para a realidade local, o que estimula a produção de resultados que melhoram a qualidade de vida dessas pessoas, pois fomentam a visão crítica e a discussão da realidade que as cercam (MIRANDA et al., 2009).

Já no projeto de Aguilar et al. (2013) sobre oficinas de contar histórias e leitura do rosto escondido, as crianças puderam usar criatividade e recursos lúdicos para discutir questões socioambientais e éticas. Além disso, na oficina de fotografia os alunos puderam lançar olhares diversos sobre sua realidade e discutir também sobre a influência da utilização do solo e da produção do lixo nas atividades cotidianas. Os professores avaliaram as oficinas de forma positiva, cuja experiência enriqueceu o conteúdo programático e propiciou o desenvolvimento de uma visão crítica não só quanto às questões ambientais, mas também quanto aos aspectos sociais da realidade desses alunos (AGUILAR et al., 2013).

O projeto Plantio da Vida, inserido na Escola Municipal Rogério Bernardes de Souza, no bairro Boa Ventura, zona rural de Inconfidentes (MG), ressaltou que a EA é um instrumento transformador que visa minimizar e solucionar a exploração desordenada dos recursos naturais. O projeto desenvolveu atividades como a importância dos insetos na natureza, a observação dos organismos do solo e o controle alternativo de saúvas na horta. $\mathrm{Na}$ primeira atividade, realizou-se um questionário antes e após a vivência (na qual os alunos se fantasiavam como insetos) para avaliar a relação dos discentes com tais animais. Na segunda, foi feito um experimento na área do pomar, com a finalidade de observar a diversidade de organismos no solo antes e depois da atividade. Já na última, utilizou-se na horta, para o controle de formigas saúvas, pão com vinagre, borra de café, cinzas e casca de ovos levados pelos alunos. Os educadores ambientais verificaram efetividade da aplicação de técnicas alternativas para o controle de pragas, sendo que, nos exercícios desenvolvidos na escola, os alunos puderam interagir com ações de EA que ampliaram, desde o primeiro momento, sua visão para ações de controle ambiental, visando a preservação dos recursos naturais (SOUSA et al., 2014).

Com base nos diversos trabalhos que desenvolvem diferentes práticas educativas voltadas para a educação ambiental, Pelicioni e Ribeiro (2005) afirmam que algumas possibilidades significativas que aprimoram a qualidade das pesquisas em educação ambiental desenvolvidas, com vistas no potencial da ação transformadora da realidade, são: desenvolvimento da visão crítica da problemática socioambiental; exercício da interdisciplinaridade; e participação ativa do educando no processo de ensino-aprendizagem. Dentro dessa perspectiva, esta pesquisa de aspecto participativo, que envolveu a comunidade escolar da região rural de Uberlândia (MG), busca desenvolver a temática "água" com o seguinte questionamento: de que modo estratégias pedagógicas melhoram a conscientização ambiental de alunos quanto ao desperdício de água nas suas atividades cotidianas, formas de contaminação e doenças de veiculação hídrica? 
Ademais, de acordo com Agudo e Tozoni-Reis (2012), o método de pesquisa-ação participativa favorece parceria coletiva entre os professores do ensino fundamental para produzir uma EA crítica no processo de alfabetização, que busca a prática de uma educação facilitadora mediante ideais democráticos e emancipatórios, tendo como consequência a construção social de conhecimentos voltados para a vida do sujeito (ressaltando as relações sujeito e ambiente e superando as relações existentes na contemporaneidade) (AGUDO; TOZONI-REIS, 2012; TRIPP, 2005). Já a abordagem conteudista-racionalista em práticas pedagógicas favorece a transmissão de conteúdos técnico-científicos com vistas às mudanças comportamentais dos indivíduos diante das questões ambientais (GUIMARÃES et al., 2012).

\subsection{Objetivos}

Partindo-se, então, dos problemas ambientais vinculados aos corpos d'água e da importância da educação ambiental como ferramenta de ensino para sensibilizar os educandos quanto ao uso consciente e racional da água, este estudo teve como objetivos:

\section{Gerais:}

- Elaborar e executar estratégias pedagógicas como prática da educação ambiental para orientar e sensibilizar educandos de escolas do campo de Uberlândia (MG), a partir da temática água, para uso consciente e racional deste recurso finito.

\section{Específicos:}

- Visitar as escolas do campo, objetos de estudo deste trabalho, para coletar informações básicas (diagnóstico da realidade) com os profissionais da educação responsáveis pelas unidades de ensino.

- Elaborar atividades pedagógicas sobre importância da água, desperdício em atividades cotidianas, contaminação, e doenças de veiculação hídrica, conforme a idade escolar dos alunos.

- Aplicar a pesquisa-ação participativa para a prática da EA e a abordagem conteudistaracionalista na realização das atividades pedagógicas envolvendo a temática água.

\section{Caminho metodológico}

O estudo foi desenvolvido com alunos do $1^{\circ}$ período da educação infantil ao $9^{\circ}$ ano do ensino fundamental de três escolas do campo localizadas na região de Uberlândia, no estado de Minas Gerais. A escolha de escolas do campo como objeto de estudo dessa pesquisa se justificou pelo limitado número de pesquisas sobre a educação do campo articulada aos princípios da EA, principalmente no estado de Minas Gerais.

Inicialmente, foram realizados contatos prévios com os funcionários da diretoria, responsáveis pelas unidades de ensino, a fim de obter consentimentos formais para realização deste estudo. Além disso, para preservar os direitos fundamentais e direitos da personalidade das unidades de ensino participantes, incluindo seus integrantes, optou-se por utilizar a nomenclatura "Escola do Campo" em toda pesquisa, conforme o artigo $5^{\circ}$ da Constituição Federal (BRASIL, 1988) e os artigos 11 a 21 do Código Civil (BRASIL, 2002).

A Escola do Campo A trabalha apenas com Ensino Fundamental (faixa etária de 6 a 16 anos) e no período matutino. A escola conta com um total de 154 alunos matriculados. A Escola do Campo B, em contrapartida, trabalha com educação infantil e ensino fundamental (faixa etária de 4 a 17 anos) e no período matutino. A escola conta com um total de 225 alunos matriculados. Por fim, a Escola do Campo C trabalha com a educação infantil e ensino 
fundamental (faixa etária de 4 a 17 anos) e no período matutino. A escola conta com um total de 207 alunos matriculados.

Para planejar as atividades educativas que seriam aplicadas conforme a idade escolar dos educandos, foi elaborado e aplicado um questionário com as seguintes informações, preenchidas pelas(os) diretoras(es): (a) quantidade de salas e alunos; (b) aulas a serem ministradas; (c) horários; (d) uso de materiais educativos conforme idade escolar (apostilas); e (e) nível de leitura dos alunos. Ademais, foi disponibilizado um espaço no questionário para que os diretores pudessem expor sugestões para as aulas. Assim, os dados obtidos foram avaliados pelos educadores ambientais e, com base neles, foi possível estruturar estratégias pedagógicas com enfoque no tema ambiental água.

Conforme os apontamentos do questionário, as aulas de EA foram planejadas em quatro grupos a partir do nível de ensino dos alunos, sendo eles: Grupo $\mathrm{I}\left(1^{\circ}\right.$ e $2^{\circ}$ períodos da educação infantil); Grupo II ( $1^{\circ}, 2^{\circ}$ e $3^{\circ}$ anos do ensino fundamental); Grupo III $\left(4^{\circ}, 5^{\circ}\right.$ e $6^{\circ}$ anos do ensino fundamental); e Grupo IV ( $7^{\circ}, 8^{\circ}$ e $9^{\circ}$ anos do ensino fundamental). De acordo com essa divisão, foram preparadas aulas didáticas abordando os seguintes temas: I Importância da água; II - Desperdício em atividades cotidianas; III - Contaminação e poluição; e IV - Doenças de veiculação hídrica.

A metodologia adotada durante as aulas de EA foi a pesquisa-ação participativa (GIL, 2002; MARCONI; LAKATOS, 2003), na qual os pesquisadores encontram-se como educadores ambientais, propondo uma estratégia didática com a utilização de aulas experimentais investigativas nas quais o aluno tem a oportunidade de construir seus conhecimentos científicos a partir de suas ideias e seus pensamentos sobre a temática água. De acordo com Brandão (2005b), a pesquisa-ação participativa é um processo de investigação e ação sobre a "realidade concreta da vida cotidiana". Além disso, este mesmo autor considera o grupo como "comunidade aprendente" (BRANDÃO, 2005a). Portanto, o estudo coletivo da realidade concreta da vida cotidiana é processo educativo coletivo participativo e emancipador.

A valorização das ideias prévias dos alunos para construção dos seus conhecimentos científicos (SILVA; AGUIAR JUNIOR, 2011) foi fundamental para despertar o interesse sobre importância da água, desperdício em atividades cotidianas, contaminação e poluição, e doenças de veiculação hídrica. Ademais, adotou-se abordagem conteudista-racionalista, que orienta o processo educativo para transmitir conhecimentos técnico-científicos sobre o ambiente, considerando que essa transmissão/assimilação tem como consequência uma relação mais adequada dos sujeitos com o ambiente. Ademais, caracterizamos a pesquisa em educação como qualitativa, pois as ações educativas envolveram uma realidade diversa, dinâmica, complexa, específica e o mais abrangente possível (TOZONI-REIS, 2008).

A aplicação das atividades pedagógicas como forma de transmitir os conhecimentos técnico-científicos visou despertar a mudança comportamental do indivíduo (comunidade escolar) diante da problemática da crise hídrica que assola o mundo. Nesse sentido, as atividades pedagógicas elaboradas e aplicadas nas três escolas do campo estão elencadas na Tabela 1, conforme a divisão de grupos proposta. 
Tabela 1 - Atividades pedagógicas estruturadas conforme a divisão de grupos proposta.

\begin{tabular}{|c|c|}
\hline & DESCRIÇÃOO \\
\hline Grupo I & $\begin{array}{l}\text { Atividade 1: Apresentação e discussão dos temas } \\
\text { Atividade 2: atividade didática Água no corpo } \\
\text { Atividade 3: atividade didática Água na natureza } \\
\text { Atividade 4: montagem do mural A importância da água } \\
\text { Atividade 5: atividade didática Ciclo da água } \\
\text { Atividade 6: entrega de lembrancinhas educativas como reforço } \\
\text { positivo. }\end{array}$ \\
\hline Grupo II & $\begin{array}{l}\text { Atividade 1: Apresentação e discussão dos temas } \\
\text { Atividade 2: atividade didática Para que serve a água? } \\
\text { Atividade 3: atividade didática Água poluída, contaminada e limpa } \\
\text { Atividade 4: montagem do mural com os cartazes produzidos na } \\
\text { Atividade 3. } \\
\text { Atividade 5: entrega de lembrancinhas educativas como reforço } \\
\text { positivo. }\end{array}$ \\
\hline Grupos III e IV & $\begin{array}{l}\text { Atividade 1: Apresentação e discussão dos temas } \\
\text { Atividade 2: atividade didática Jogo de perguntas e respostas } \\
\text { Atividade 3: vídeos educativos sobre o assunto água (O uso racional } \\
\text { da água e Água: as doenças causadas pela contaminação) } \\
\text { Atividade 4: atividade didática Experimento prático sensorial das } \\
\text { características da água } \\
\text { Atividade 5: entrega de lembrancinhas educativas como reforço } \\
\text { positivo. }\end{array}$ \\
\hline
\end{tabular}

Portanto, os resultados observados durante as intervenções (realização das estratégias pedagógicas) em cada grupo foram analisados e discutidos articulando-os com os referenciais teóricos que remetem aos princípios da educação ambiental.

\section{Resultados e discussão}

As estratégias pedagógicas aqui adotadas podem ser melhor identificadas ao longo da apresentação dos principais resultados do trabalho, uma vez que todo o processo educativo se constituiu a partir das demandas aludidas por cada grupo de alunos ao longo da pesquisa e intervenção, atendendo aos objetivos da EA quanto à construção do conhecimento de forma coletiva, conforme defendido por Souza et al. (2011). Os resultados desta pesquisa foram dispostos em categorias de forma a facilitar a visualização e discussão dos dados obtidos nas três escolas do campo estudadas até o momento, segundo os subitens a seguir.

\subsection{Análise da estratégia pedagógica adotada para o Grupo I}

Observando os relatos dos alunos das escolas do campo B e C na Atividade 1, verificou-se que todos sabiam alguma informação pertinente em relação à temática água, principalmente no que se refere à higienização, a doenças e à produção agrícola. Este momento de abordagem comunicativa dialógica, segundo Silva e Aguiar Junior (2011), foi importante ao passo que permitiu resgatar ideias preliminares dos estudantes sobre o tema e, 
assim, provocou explicações sobre os conceitos e eventos (senso comum) em explicações mais abrangentes (conhecimento científico).

Percebe-se, ainda, que a estratégia de levantar conhecimentos prévios dos alunos sobre o tema foi fundamental para conduzir as atividades subsequentes, uma vez que foi possível verificar explicações mais elaboradas (caráter científico) ao longo das atividades propostas. Isso também foi observado por Silva e Aguiar Junior (2011), os quais verificaram que a eficácia do planejamento e organização da sequência de ensino está no levantamento preliminar de conhecimentos prévios dos alunos acerca do tema água.

Sobre a presença de água na composição do corpo humano (Atividade 2), a maioria dos alunos entendeu e representou em desenho do cartaz que $75 \%$ do corpo é composto de água. No entanto, alguns ilustraram o corpo humano sendo 100\% composto de água (Figura 1C). Conforme os relatos dos próprios alunos aos educadores ambientais, todo o corpo deve apresentar água porque esta é essencial para o funcionamento pleno de todos os órgãos que o compõem (conceito alternativo criado pelos alunos, isto é, um conceito certo, porém visto sob uma diferente perspectiva). Para auxiliar os alunos a construir o conceito científico de que o corpo humano contém $75 \%$ de sua composição em água, os educadores ambientais utilizaram figuras ilustrativas em projeção de slides que mostravam como a água está distribuída no corpo. Os órgãos com mais água são os pulmões (mesmo se vivem cheios de ar) e o fígado, ambos totalizando $86 \%$ de água, que, paradoxalmente, têm mais água do que o próprio sangue (81\%). O cérebro, os músculos e o coração são constituídos por $75 \%$ de água (MIRANDA, 2004).

É nesse contexto de discussão da saúde coletiva aliado aos recursos hídricos que a EA se torna importante instrumento para promover o diálogo, uma vez que suas ações determinam, condicionam e impactam favoravelmente para melhor qualidade de vida das pessoas (PICCOLI et al., 2016).

Quanto à qualidade ambiental da água discutida na Atividade 3, os educadores ambientais ressaltaram aos alunos a importância da água limpa, pois se estiver em condições inadequadas (poluída e/ou contaminada) pode comprometer a existência do ecossistema, assim como a saúde do ser humano. Para entender os conceitos de água poluída e contaminada já existentes na percepção dos alunos, os educadores ambientais fizeram várias perguntas a eles. Observou-se nas respostas que os estudantes associavam água poluída e contaminada como sinônimos e, por isso, os educadores ambientais interviram na situação usando exemplos do cotidiano para construir os conceitos científicos em conjunto. Aguiar e Farias (2017) relatam que a participação dos alunos com os professores na elaboração de critérios avaliativos para a aprendizagem em EA é fundamental para problematizar e elencar posturas a ser aprendidas e, posterior à atividade educativa, poder ser adotadas como referência pelo coletivo.

Por outro lado, Dacache (2004) ressalta que a mudança comportamental de alunos, pais e escola diante da problemática da qualidade da água pode ser alcançada mediante a prática da educação ambiental, que envolve princípios de Ecologia, assim como a própria ação da escola (com projetos ambientalistas) no processo de ensino e aprendizagem.

$\mathrm{Na}$ Atividade 4, os alunos das duas escolas do campo foram orientados a colarem os materiais educativos finalizados nas Atividades 2 e 3 em um mural montado nas escolas, como meio de socializar os trabalhos educativos produzidos. A construção e socialização de materiais educativos (cartazes, desenhos e outros) em práticas pedagógicas voltadas para a EA, conforme citado por Cavalheiro e Nishijima (2014), é uma forma de registrar os conceitos e as informações aprendidas e ressignificá-las, promovendo a troca de informações e ideias entre grupos de alunos, conforme preconiza o método de pesquisa-ação participativa.

Ainda sobre o uso de ferramentas educativas aliadas à EA, Martins et. al (2015), por exemplo, observaram que o uso de estratégias como palestras, cartilha educativa e conversas 
informais envolvendo a temática preservação e manejo da água foram fundamentais para despertar a preocupação de alunos, pais, professores e funcionários de uma escola pública de Uberlândia (MG) e, assim, provocar a mudança de hábitos com relação ao uso da água.

Com relação à atividade sobre o ciclo da água (Atividade 5), os alunos se mostraram bastante empolgados e curiosos durante a montagem das etapas do ciclo hidrológico. Por isso, o uso da abordagem conteudista-racionalista pelos educadores ambientais durante a atividade proporcionou melhor discussão dos assuntos ou conceitos científicos a respeito do ciclo e, ainda, favoreceu a formação destes alunos, mais conscientes e ativos. Cabe ressaltar que a professora regente da Escola do Campo B disse que utilizaria as atividades propostas sobre a temática água como atividade avaliativa na disciplina que ministra aos alunos do $2^{\circ}$ período. Para Freitas e Marin (2015), professores comprometidos e de formação adequada sobre o tema água favorecem a formação de espaços educativos e a sensibilização de educandos, docentes e sociedade em geral quanto às questões ambientais.

Portanto, o uso do método de pesquisa-ação participativa durante a realização das estratégias pedagógicas aqui relatadas foi alternativa metodológica interessante e de cunho qualitativo (RUFINO; DARIDO, 2010) para a inserção da EA no contexto escolar, pois possibilitou aos educadores ambientais articular ensino e pesquisa, reflexão sistemática e prática docente, que são característicos da EA crítica e transformadora (RHEINHEIMER; GUERRA, 2009).

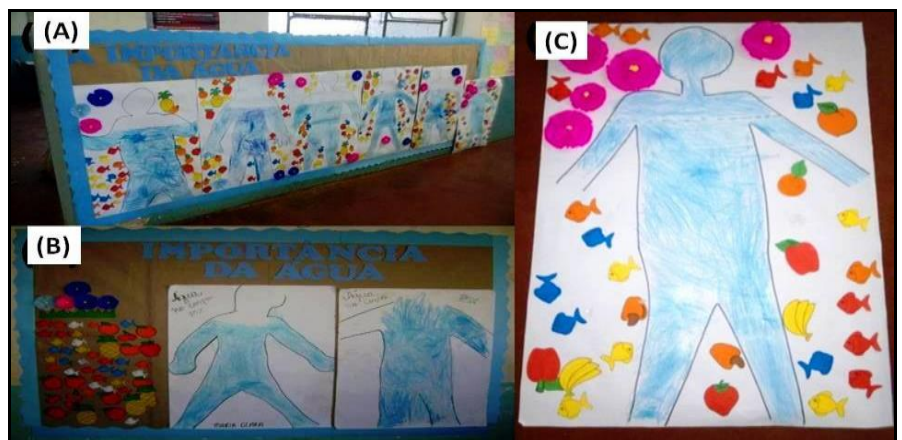

Figura 1 - (A) Atividade Água no corpo realizada pela Escola do Campo B. (B) Atividade Água no corpo realizada pela Escola do Campo C. (C) Corpo humano pintado 100\% por um dos grupos de alunos da Escola do Campo B.

Fonte: Pesquisa de campo.

\subsection{Análise da estratégia pedagógica adotada para o Grupo II}

No início da aula (Atividade 1), quando os alunos foram indagados sobre os temas da proposta pedagógica, muitos se mostraram bastante interessados, inclusive fazendo menção a casos de familiares que adquiriram dengue devido à água parada. Além disso, reportaram a importância da água para o mundo, principalmente para os setores de agricultura, higienização e hidratação dos seres humanos. Já os estudantes menos participativos durante esses questionamentos preliminares foram induzidos pelos educadores ambientais, por meio do diálogo, a interagir e contribuir com a construção do conhecimento, conforme objetiva a pesquisa-ação participativa. As metodologias pedagógicas sugerem que quando conciliam a teoria com a prática, o aprendizado é mais facilmente absorvido pelos alunos (SOUZA et al., 2011).

Sobre as principais atividades cotidianas em que se tem o uso da água (Atividade 2), os alunos apontaram, por meio de desenhos feitos em uma gota d'água feita de papel sulfite, atividades relacionadas à higienização (escovar os dentes e tomar banho) e à agricultura (produção de alimentos). Essa atividade visou aplicar a categoria central de análise da 
pesquisa-ação participativa, que é a busca da compreensão da prática cotidiana pela açãoreflexão-ação. Carvalho (2004) cita que a pesquisa-ação participativa em educação ambiental é uma metodologia de investigação e ação sobre processos formativos, cujo maior objetivo é a formação do sujeito ecológico, compreendendo a investigação e a ação como coletivas, participativas, conscientizadoras, emancipatórias e, principalmente, fundamentadas na práxis.

Já em relação aos assuntos "poluição" e "contaminação", na Atividade 3 os alunos confeccionaram um cartaz sobre a qualidade da água (limpa, poluída e contaminada) a partir da colagem de figuras representativas. A maioria dos alunos (Escola do Campo A) definiu água poluída como aquela que contém poluentes; água contaminada como aquela com microorganismos; e água limpa como a apropriada para se beber. Em contrapartida, alguns alunos (Escola do Campo B) apontaram definições de água poluída e água limpa similares aos conceitos expostos anteriormente, porém não sabiam definir água contaminada, inclusive, associavam água poluída e contaminada como a mesma coisa. Assim, os educadores ambientais intervieram nessa situação-problema realizando explicações e citando exemplos das três classificações de águas existentes e suas principais diferenças. Os alunos da Escola do Campo $\mathrm{C}$, diferentemente das outras, diziam que água poluída se refere àquela que contém lixo; água contaminada, àquela que contém bichinhos; e a água limpa, àquela para beber, ou seja, estes alunos definiram corretamente os diferentes tipos de água, mas utilizaram vocabulário rudimentar.

Para contextualizar essas definições, uma das educadoras ambientais mencionou o desastre ambiental da barragem de Fundão, na cidade de Mariana (MG) para que os alunos pudessem entender que a lama de rejeitos (metais tóxicos), por exemplo, é uma forma de contaminação da água.

O uso de oficinas de educação ambiental fundamentadas em temáticas como poluição e uso racional da água, como mencionado por Querioz et. al (2016), foi essencial para despertar interesse dos alunos ao longo das propostas didáticas (oficinas), a curiosidade sobre os assuntos abordados e, principalmente, a percepção de problemas ambientais na realidade local dos estudantes.

Após a finalização de todas as atividades pedagógicas, os alunos das três escolas foram orientados pelos educadores ambientais a montarem um mural com todos os materiais educativos produzidos (Figura 2). Essa estratégia pedagógica tinha por finalidade promover a socialização dos conhecimentos adquiridos pelos estudantes durante as atividades práticas com todos os frequentadores das escolas investigadas, inclusive com outros funcionários.

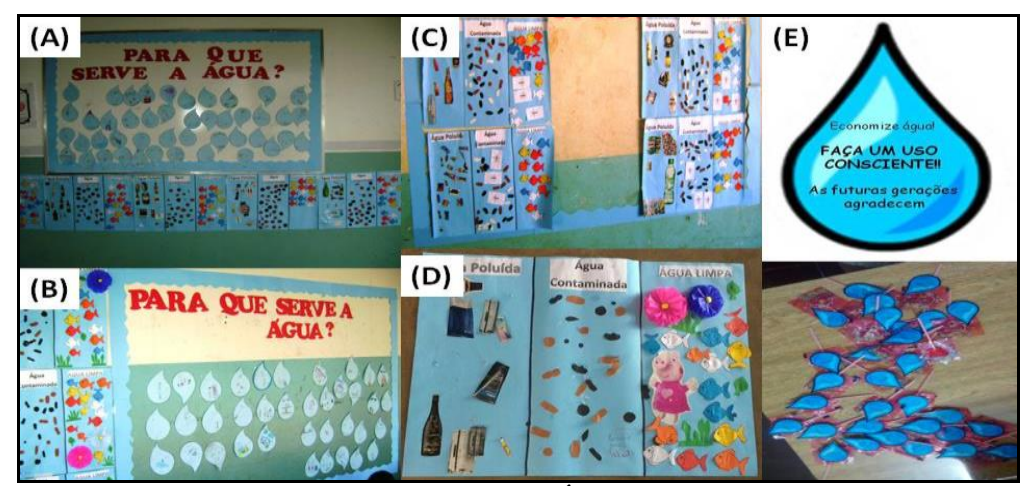

Figura 2 - (A) Atividades Para que serve a água? e Água poluída, contaminada e limpa da Escola do Campo A. (B) Atividades Para que serve a água? e Água poluída, contaminada e limpa da Escola do Campo B. (C) Atividade Para que serve a água? da Escola do Campo C. (D) Colagem da figura da Peppa Pig na água limpa. (E) Lembrancinha entregue a todos os alunos de todas as escolas do campo. Fonte: Pesquisa de Campo. 


\subsection{Análise da estratégia pedagógica adotada para os Grupos III e IV}

Durante a discussão inicial dos temas a serem abordados na aula (Atividade 1), os educadores ambientais puderam perceber que os alunos do Grupo III já detinham o conhecimento de cerca de $80 \%$ do conteúdo apresentado, principalmente porque um dos alunos relatou que a escola promoveu uma semana de combate ao Aedes Aegypti com a participação dos próprios educandos. Os discentes também foram atentos e participativos à apresentação dos temas, sobretudo aos assuntos relacionados à importância da água, ao seu uso e ao desperdício. Os assuntos que mais chamaram atenção dos alunos foram: produção de energia em hidrelétricas; escassez de água devido ao desperdício em atividades cotidianas; e a qualidade da água (contaminação e poluição).

Para os alunos do Grupo IV, o assunto que chamou mais atenção foi o fato do desmatamento ser um dos fatores que contribuem para a escassez da água no mundo. Em função disso, educadores ambientais explicaram como o desmatamento causa a escassez da água, ressaltando a função das árvores na regulação de água no subsolo. Embora alguns alunos deste grupo tenham demonstrado desinteresse ao longo da aula, foi possível observar participações ativas e empolgadas da maioria dos estudantes que permitiram construir conhecimentos científicos a respeito de assuntos como geração de energia elétrica e produção agrícola.

Dando sequência à aula, na Atividade 2, os alunos participaram do Jogo de perguntas e respostas, em que tinham que responder perguntas objetivas e discursivas a fim de resgatar conhecimentos adquiridos em sala. Os alunos dos Grupos III e IV, de maneira geral, corresponderam ao objetivo da atividade, inclusive relataram diversas atividades de economia de água que os seres humanos devem praticar diariamente, tais como: fechar o chuveiro enquanto tomamos banho; fechar a torneira enquanto lavamos as mãos; não tomar banhos demorados; não lavar o carro com torneira aberta; escovar os dentes com a torneira fechada; lavar o carro com balde; e consertar vazamentos.

Com relação aos recursos hídricos, um dos alunos do Grupo III disse que está em nossas mãos a existência ou não desse recurso para o Planeta Terra. Em contrapartida, a maioria dos alunos do Grupo IV afirma que a água vai acabar em função da falta de consciência do ser humano. Esses relatos revelaram que os alunos tiveram certo impacto quando os educadores enfatizaram, por meio de slides, a quantidade desperdiçada de água em certas atividades do cotidiano. Inclusive, a maioria disse que a água um dia pode faltar em função das ações danosas (contaminação, poluição e desperdício dos recursos hídricos disponíveis) dos seres humanos. Isso mostra que os discentes percebem que ações que contaminam, poluem e tornam a água escassa podem ocasionar sua falta em um futuro não tão distante.

Nicoletti e Sepel (2013) apontam que jogos didáticos sobre o tema água para o público do ensino fundamental são boas alternativas que aumentam a motivação e criatividade dos estudantes, podendo ser utilizados como instrumento educativo para recuperar ou desenvolver habilidades no alunado e potencializar o desempenho em conteúdos mais difíceis. Entretanto, os autores reforçam que jogos didáticos não são substitutos de outros métodos de ensino, uma vez que tais recursos didáticos são apenas suporte para o trabalho do professor em sala de aula e para os alunos, um mecanismo poderoso para motivar a aprendizagem.

No intuito de reforçar os assuntos abordados em sala de aula, a Atividade 3 consistiu na apresentação de vídeos educativos produzidos e divulgados pela internet que abordavam o tema "água" (Tabela 1, atividade 3). De maneira geral, os alunos das três escolas do campo ficaram bastante atentos aos vídeos e demonstraram conhecimento principalmente sobre a dengue, Zika vírus e febre Chikungunya. 
Aguilar et al. (2013) relatam que ações de educação ambiental vinculadas a atividades lúdicas (vídeos, oficinas, fotografias e outros) estimulam a visão crítica e a discussão dos alunos sobre a realidade que os cercam (questões ambientais).

$\mathrm{Na}$ Atividade 4, foi desenvolvido Experimento prático sensorial das características da água, cujo objetivo foi fazer que os alunos identificassem três características intrínsecas da água por meio de um experimento sensorial e visual (uso dos sentidos olfato e visão). Os alunos do Grupo III (escolas do campo A e B) e do Grupo IV (escolas do campo A e C) fizeram caretas ao sentirem o odor da amostra de água contendo vinagre, que até então julgavam como limpa, portanto, desconheciam a presença dessa substância na água (Figura 3D). Quando foram questionados quais das águas expostas eles utilizariam para beber, eles responderam a "terceira amostra", que não continha cheiro e nem coloração escura. Mediante tais relatos, os educadores ambientais ressaltaram aos alunos que a água apresenta três características fundamentais: incolor, inodora e insípida (Figura 3). Em seguida, explicaram que a água destinada ao consumo não pode conter cheiro, gosto e nem aspecto visual alterado, pois se alguma dessas características não for respeitada, significa que esse recurso hídrico apresenta algum tipo de contaminação e/ou poluição. Nesse sentido, Pereira et al. (2016) reforçam que o tratamento de água para consumo humano é uma das medidas mais importantes de controle ambiental para a preservação da saúde.

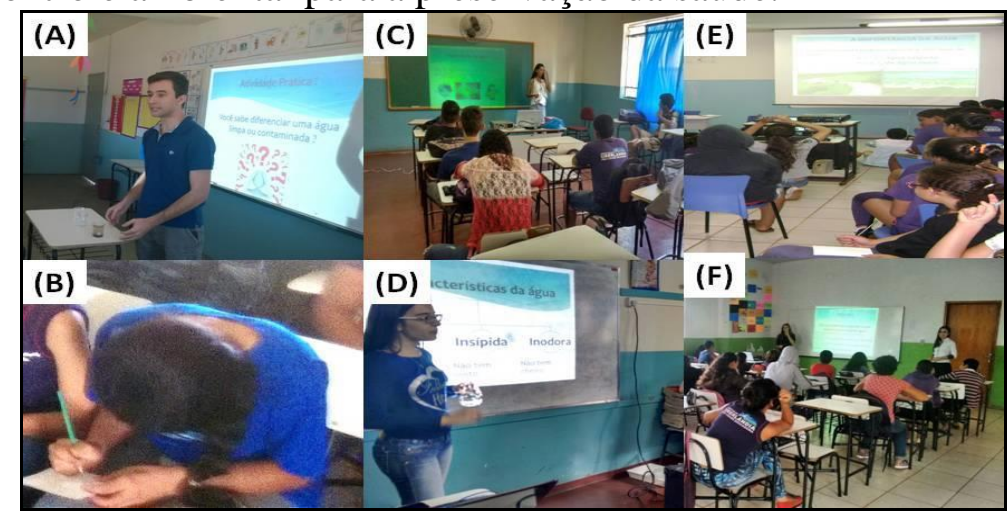

Figura 3 - (A) Educador ambiental apresentando a atividade didática Experimento prático sensorial das características da água na Escola do Campo A. (B) Aluna da Escola do Campo A realizando a atividade Jogo de perguntas e respostas. (C) Educador ambiental avaliando as respostas dos alunos da

Escola do Campo B na atividade Jogo de perguntas e respostas. (D) Educadora ambiental apresentando a atividade Experimento prático sensorial das características da água para os alunos da Escola do Campo B. (E) Educador ambiental apresentando os temas aos alunos da Escola do Campo

C. (F) Alunos da Escola do Campo C realizando a atividade Jogo de perguntas e respostas. Fonte: Pesquisa de campo.

Essa atividade experimental, assim como as anteriores, foi fundamental para os alunos aprenderem sobre os temas e não simplesmente decorá-los, pois, conforme relatos de Silva (2008), é imprescindível o uso de propostas alternativas para desenvolver o espírito crítico e o raciocínio dos alunos. Estratégias didáticas fundamentadas na EA e incluídas na rotina das aulas, segundo Freitas e Zaú (2015), impulsionam os alunos a maior percepção e compreensão das questões ambientais, principalmente as de sua localidade. Ademais, Souza et al. (2011) afirmam que a pesquisa participante amplia o comprometimento de todos quanto à necessidade de mudanças da realidade socioambiental em que os indivíduos estão inseridos.

Para Schünemann e Rosa (2010), uma maior participação dos alunos se deve às estratégias de ensino adotadas para abordar o tema e, assim, alcançar o objetivo da aula. 


\subsection{Entrega de lembrança educativa para potencializar a conscientização dos educandos}

Segundo Tozoni-Reis (2008), a relação entre educação e conscientização está muito presente nas propostas de educação ambiental, mas há uma falta de precisão conceitual no que diz respeito à conscientização. De acordo com Freire (1980), conscientização implica em ultrapassar a esfera espontânea de apreensão da realidade para atingir a esfera crítica na qual a realidade se dá como objeto cognoscível e na qual o homem assume posição epistemológica. Então, a pesquisa-ação participativa em educação ambiental tem como princípios teóricometodológicos a participação, o processo coletivo, a conscientização e a relação entre teoria e prática. Tendo isso em vista, ao final das aulas, em todos os grupos, foram entregues aos alunos lembranças educativas (contendo um recado como reforço positivo), que visava orientar e sensibilizar os alunos sobre a temática desenvolvida: "Economize água! Faça um uso consciente!! As futuras gerações agradecem". Tal estratégia tinha o intuito de reforçar positivamente a importância de se cuidar dos recursos hídricos disponíveis, pois, segundo Kumar (2013), a participação das pessoas na resolução de problemas ambientais ajuda tanto as gerações atuais quanto as futuras.

Os alunos foram instruídos a não jogar o papel com o recado educativo no lixo e sim a guardar e depois mostrar para seus pais e, assim, estender essa discussão sobre a importância da água em seus lares. Portanto, aliar a temática água ao contexto de alunos que residem em comunidades rurais, por meio da EA, é uma forma de mostrar-lhes a importância do recurso, bem como das ações individuais para preservação e uso consciente (AGUIAR et al., 2015).

\section{Considerações finais}

As propostas pedagógicas aplicadas nas três escolas do campo até então atendidas, em Uberlândia (MG), exploraram a conscientização dos alunos em relação à poluição, à contaminação, à importância, a doenças e ao uso inapropriado da água com enfoque na utilização cotidiana do recurso hídrico. Atividades envolvendo a teoria conciliada à prática cotidiana despertou o interesse dos alunos da educação infantil a preservarem a água, confirmados nos debates durante e após as aulas. A adoção do método de pesquisa-ação participativa favoreceu a participação dos envolvidos, garantindo-lhes tomada de decisões coletivas em todo o processo e produzindo conhecimentos ambientais e pedagógicos. A proposta metodológica aplicada tratou temas ambientais como geradores de reflexão e ação sobre o ambiente, contribuindo para o processo de conscientização numa prática construída de forma coletiva e compartilhada.

Os estudantes de todas as séries se mostraram interessados com a exposição de assuntos sobre o recurso hídrico, destacando-se maior participação da turma do $6^{\circ}$ ano da Escola do Campo $\mathrm{C}$ durante os debates e atividades, visto que se mostraram curiosos sobre a questão das doenças vinculadas à água e sua contaminação ao relatarem situações sobre suas vivências a respeito da dengue.

A abordagem conteudista-racionalista adotada nas atividades pedagógicas de EA deste trabalho valorizou os conhecimentos alternativos dos alunos para a construção dos conhecimentos científicos a respeito do tema água e, sobretudo, considerou o processo de transmissão e assimilação como sendo essencial para a mudança comportamental mais adequada dos sujeitos com o ambiente.

As propostas pedagógicas aqui adotadas para a prática da EA em escolas do campo permitiram a junção dos conhecimentos científicos por parte dos educadores ambientais com os do senso comum por parte dos alunos, favorecendo o aprendizado coletivo pela troca de ideias. Em especial, as atividades didáticas que envolviam a produção de materiais educativos pelos alunos mostraram-se mais motivadoras do que a discussão inicial do tema nas aulas 
devido ao interesse que estudantes apresentaram durante a execução das atividades práticas. Enfim, para que seja alcançado o objetivo da conscientização, não basta somente abordar o assunto com métodos didáticos motivadores em determinadas aulas, mas sim que haja uma ação contínua, de forma que professores e escola mantenham um reforço contínuo sobre a problemática da crise hídrica que assola boa parte do mundo, e até mesmo o Brasil, em suas aulas ao longo do ano escolar.

Agradecimentos: Fapemig (processos APQ 02249-14 e APQ 03219-14), Rede Mineira de Química e CNPq.

\section{Referências}

AGUDO, M. de M.; TOZONI-REIS, M. F. de C. Educação ambiental na escola: pesquisa-ação a partir do conto "A maior flor do mundo" de José Saramago. XVI ENDIPE - Encontro Nacional de Didática e Práticas de Ensino. UNICAMP, Campinas, 2012. 12p.

AGUIAR, J. P. et al. Educação ambiental para a conservação dos recursos hídricos por meio de atividade de ensino com pesquisa em uma escola pública no Pará. Revista Brasileira de Educação Ambiental, São Paulo, v. 10, n. 4, p. 88-98, 2015.

AGUIAR, W. J.; FARIAS, C. R. O. Apontamentos para práticas de avaliação na educação ambiental em diálogo com saberes de professores da educação básica. Pesquisa em Educação Ambiental, São Paulo, v. 12, n. 1, p. 10-25, 2017.

AGUILAR, T. M. et al. Oficinas de educação ambiental do Projeto Pato Aqui, Água Acolá em escolas de São Roque de Minas, Minas Gerais, Brasil. E-Scientia, Belo Horizonte, v. 6, n. 1, p. 16-35, 2013.

BEZERRA, A. A. Fragmentos da história da educação ambiental (EA). Dialógica, Manaus, v. 1, n. 3, p. 1-6, 2007.

BRANDÃO, C. R. Comunidades aprendentes. In: FERRARO JÚNIOR, L. A. (Coord.). Encontros $e$ caminhos: formação de educadoras(es) ambientais e coletivos educadores. Brasília, DF: MMA, 2005a. p. 85-91.

BRANDÃO, C. R. Pesquisa participante. In: FERRARO JÚNIOR, L. A. (Coord.). Encontros $e$ caminhos: formação de educadoras(es) ambientais e coletivos educadores. Brasília, DF: MMA, 2005 b. p. 259-266.

BRASIL. Constituição (1988). Constituição da República Federativa do Brasil. Diário Oficial da União, Poder Legislativo, Brasília, DF, 5 out. 1988. Seção 1, p. 1.

BRASIL. Lei $\mathrm{n}^{\circ}$ 10.406, de 10 de janeiro de 2002. Institui o Código Civil. Diário Oficial da União, Poder Legislativo, Brasília, DF, 11 jan. 2002. Seção 1, p.1

CARVALHO, I. C. M. Educação ambiental: a formação do sujeito ecológico. 1. ed. São Paulo: Cortez, 2004.

CAVALHEIRO, L. W.; NISHIJIMA, T. Uma situação de estudo como estratégia de educação ambiental à abordagem da problemática dos riachos degradados em uma escola. Pesquisa em Educação Ambiental, São Paulo, v. 9, n. 2, p. 10-22, 2014.

DACACHE, F. M. Uma proposta de Educação Ambiental utilizando o lixo como tema interdisciplinar. 2004. 90 f. Dissertação (Mestrado em Ciência Ambiental) - Universidade Federal Fluminense, Niterói, 2004.

FREIRE, P. Conscientização. São Paulo: Moraes, 1980. p. 26. 
FREITAS, N. T. A.; MARIN, F. A. D. G. Educação ambiental e água: concepções e práticas educativas em escolas municipais. Nuances: Estudos sobre Educação, Presidente Prudente-SP, v. 26, número especial 1, p. 234-253, Jan. 2015.

FREITAS, J. R. S.; ZAÚ, A. S. Educação ambiental a partir da interação entre a sala de aula e arredores da comunidade. Revista Brasileira de Educação Ambiental, São Paulo, v. 10, n. 2, p. 249$269,2015$.

GIL, A. C. Como elaborar projetos de pesquisa. 4. ed. São Paulo: Atlas, 2002.

GUIMARÃES, Z. F. S. et al. Projetos de educação ambiental em escolas: a necessidade da sistematização para superar a informalidade e o improviso. Pesquisa em Educação Ambiental, São Paulo, v. 7, n. 1, p. 67-84, 2012.

KUMAR, S. Environmental awareness among rural folks of Hamirpur District, H.P. The International Journal of Engineering and Science, Massachusetts, v. 2, n. 1, p. 81-84, 2013.

LOUREIRO, C. F. B. Trajetórias e fundamentos da educação ambiental. 3. ed. São Paulo: Cortez, 2009.

MARCONI, M. A.; LAKATOS, E. M. Fundamentos de metodologia científica. 5. ed. São Paulo: Atlas, 2003.

MARTINS, G. A. F. et al. Estudo epidemiológico e da qualidade da água de uma escola de ensino fundamental do município de Uberlândia, Minas Gerais: aspectos ambientais e sociais. Em Extensão, Uberlândia, v. 14, n. 2, p. 104-121, 2015.

MIRANDA, E. E. A água no corpo humano. Campinas, 2004. Disponível em: <https://goo.gl/By93wm> Acesso em: 22 fev. 2017.

MIRANDA, S. et al. Projeto de avaliação da educação ambiental nas escolas de ensino fundamental do município de Benevides Murinim. In: CONGRESSO DE PESQUISA E INOVAÇÃO DA REDE NORTE E NORDESTE DE EDUCAÇÃO TECNOLÓGICA, 4., 2009, Belém. Anais... Belém: Instituto Federal do Pará, 2009.

MORAES, D. S. L.; JORDÃO, B. Q. Degradação de recursos hídricos e seus efeitos sobre a saúde humana. Revista de Saúde Pública [on-line], São Paulo, v. 36, n. 3, p. 370-374, 2002.

NICOLETTI, E. R.; SEPEL, L. M. N. Detetives da água: desenvolvimento de jogo didático para o ensino fundamental. In: ENCONTRO NACIONAL DE PESQUISA EM EDUCAÇÃO EM CIÊNCIAS, 9., 2013, Águas de Lindóia. Atas... Águas de Lindóia: ENPEC, 2013.

PELICIONI, A. F.; RIBEIRO, H. Capacitação, representação social e prática em educação ambiental. Revista Brasileira de Ciências Ambientais, Rio de Janeiro, n. 2, p. 21-24, 2005.

PEREIRA, J. O. et al. Impacto do consumo descontrolado de água na produção de resíduos em estação de tratamento de água. Estudo de caso: ETA-Itacolomi, Ouro Preto (MG). Revista Brasileira de Ciências Ambientais, Rio de Janeiro, n. 39, p. 2-13, 2016.

PICCOLI, A. S. et al. A educação ambiental como estratégia de mobilização social para o enfrentamento da escassez de água. Ciência e Saúde Coletiva [on-line], Rio de Janeiro, v. 21, n. 3, p. 797-808, 2016.

QUERIOZ, T. L. S. et al. Uma proposta interdisciplinar de educação ambiental a partir do tema água. Revista Brasileira de Extensão Universitária, Chapecó, v. 7, n. 1, p. 15-22, 2016.

RHEINHEIMER, C. G.; GUERRA, T. Pesquisa grupal, pesquisa-ação-participativa e educação ambiental: uma parceria que deu certo. Revista eletrônica do Mestrado em Educação Ambiental, Rio Grande, v. 22, p. 417-438, jan./jul. 2009. 
ROTHMAN, F. D. et al. Educação ambiental a partir de uma abordagem crítica: ferramenta para o fortalecimento da organização de comunidades ribeirinhas. In: CONGRESSO BRASILEIRO DE EXTENSÃO UNIVERSITÁRIA, 2., 2004, Belo Horizonte. Anais... Belo Horizonte, 2004.

RUFINO, L. G. B.; DARIDO, S. C. A pesquisa-ação como forma de investigação no âmbito da educação física escolar. In: SEMINÁRIO INTERNACIONAL DE PESQUISA E ESTUDOS QUALITATIVOS, 4., 2010, Rio Claro. Anais... Rio Claro: SIPEQ, 2010. p. 1-9.

SANTANA, A. C.; FREITAS, D. A. F. Educação ambiental para conscientização quanto ao uso da água. Revista eletrônica do Mestrado em Educação Ambiental, Rio Grande, v. 28, p. 178-188, 2012.

SANTOS, M. M. C. dos et al. Educação ambiental e o homem do campo: Vivências a partir de classes multisseriadas. in: XVI Encontro Nacional dos Geógrafos, 2010, Porto Alegre. Anais. Porto Alegre: ISBN, 2010. p. 1 - 11. Disponível em: <file:///D:/Downloads/download(1581) (1).PDF>. Acesso em: 13 jun. 2016.

SCHÜNEMANN, D. R.; ROSA, M. B. Conscientização ambiental na educação infantil. Revista Eletrônica do PPGEAmb-CCR/UFSM, Santa Maria, v. 1, n. 1, p. 122-132, 2010.

SIDDIQUI, T. Z.; KHAN, A. Environment education: an Indian perspective. Research Journal of Chemical Sciences, Massachusetts, v. 5, n. 1, p. 1-6, 2015.

SILVA, A. C. S. O trabalho com educação ambiental em escolas de ensino fundamental. Revista eletrônica do Mestrado em Educação Ambiental, Rio Grande, v. 20, p. 37-52, jan./jun. 2008.

SILVA, A. F.; AGUIAR JUNIOR, O. G. Água na vida cotidiana e nas aulas de ciências: análise de interações discursivas e estratégias didáticas de uma professora dos anos iniciais do ensino fundamental. Investigações em Ensino de Ciências, Porto Alegre, v. 16, n. 3, p. 529-547, 2011.

SOUSA, J. S. et al. Educação ambiental em escola da zona rural como instrumento para o controle ambiental. In: CONGRESSO BRASILEIRO DE ENGENHARIA AGRÍCOLA, 43., 2014, Campo Grande. Anais... Campo Grande: Conbea, 2014.

SOUZA, D. C.; SALVI, R. F. A pesquisa em educação ambiental: um panorama sobre sua construção. Revista Ensaio, Belo Horizonte, v. 14, n. 3, p. 111-129, 2012.

SOUZA, E. F. de et al. Educação ambiental, ludicidade e pesquisa participante no ensino fundamental. Revista Brasileira de Ciências Ambientais, n. 21, p. 14-23, 2011.

TOZONI-REIS, M. F. C. Pesquisa-ação em educação ambiental. Pesquisa em Educação Ambiental, São Paulo, v. 3, n. 1, p. 155-169, 2008.

TRIPP, D. Pesquisa-ação: uma introdução metodológica. Educação e Pesquisa, São Paulo, v. 31, n. 3, p. 443-466, set./dez. 2005. 